\title{
Conductivity and Superconductivity in Granular Materials
}

\author{
M. Gazda, B. Kusz, J. Gackowska and W. SAdowski
}

Gdańsk University of Technology, Faculty of Applied Physics and Mathematics

Narutowicza 11/12, 80-952 Gdańsk, Poland

\begin{abstract}
Granular metals and superconductors are very interesting materials thanks to their untypical electrical properties caused by the presence of the Coulomb effects, electron and Cooper pair tunnelling and various aspects of disorder. Most typical and widely studied representatives of this group consist of low $T_{\mathrm{c}}$ superconductor granules distributed in insulating matrix (e.g. lead in germanium matrix). In comparison with them a system of granules of high- $T_{\mathrm{c}}$ superconductors embedded in an insulating matrix is more difficult to be experimentally realised. ( $\mathrm{Bi}, \mathrm{Pb})-\mathrm{Sr}-\mathrm{Ca}-\mathrm{Cu}-\mathrm{O}$ materials obtained with solid state crystallisation method may be considered as an example of granular and disordered metals and superconductors. Solid state crystallisation of initially amorphous material leads to formation of 2201 and 2212 granules embedded in the insulating or semiconducting matrix. Further annealing causes increase in size and/or the number of conducting grains and decrease in the width of the insulating barriers between them. In both cases of low- and high- $T_{\mathrm{c}}$ granular materials the main parameters, which determine their properties, are the amount of metallic phases and the tunnelling conductivity between the neighbouring grains. In this work some properties of low- and high- $T_{\mathrm{c}}$ granular materials are discussed and compared.
\end{abstract}

PACS numbers: 74.81.Bd, 62.23.Pq

\section{Introduction}

Granular materials are very interesting from the point of view of their transport properties. They consist of conducting grains randomly dispersed in an insulating or semiconducting matrix. The grain sizes may be between a few and hundreds nanometres. Such materials have been studied for quite a long time (e.g. [1-6]). Granular materials in which metallic grains transit into the superconducting state may have even more interesting properties since not only a single electron hopping but also the Cooper pair hopping is possible below critical temperature. Main features which determine properties of granular materials are the tunnelling conductivity between the neighbouring grains and the relations between energies characteristic of the system [7]. 
There are several experimental methods, which may be applied to produce a granular material. They are, for example, co-sputtering of a metal and insulator, evaporation of a metal in a controlled oxygen atmosphere, sol-gel coating and various procedures of heat-treatment in the solid state. In this work granular superconductors obtained by the modification of amorphous materials are studied. Both low- and high- $T_{\mathrm{c}}$ granular materials are presented and compared.

\section{Experimental}

Two groups of samples have been prepared. High- $T_{\mathrm{c}}$ granular samples were produced by the solid state crystallisation. First, the samples of $\left(\mathrm{Bi}_{0.8} \mathrm{~Pb}_{0.2}\right)_{4} \mathrm{Sr}_{3} \mathrm{Ca}_{3} \mathrm{Cu}_{4} \mathrm{O}_{x}$ glass were prepared from reagent grade: $\mathrm{Bi}\left(\mathrm{NO}_{3}\right)$. $5 \mathrm{H}_{2} \mathrm{O}, \mathrm{PbO}, \mathrm{CuO}, \mathrm{Sr}\left(\mathrm{NO}_{3}\right)_{2}$ and $\mathrm{CaCO}_{3}$. The substrates were mixed in the $(\mathrm{Bi}, \mathrm{Pb}): \mathrm{Sr}: \mathrm{Ca}: \mathrm{Cu}$ ratio $4: 3: 3: 4$ and calcinated at $820^{\circ} \mathrm{C}$ for $10 \mathrm{~h}$. Then, they were melted in a platinum crucible at $1250^{\circ} \mathrm{C}$, kept in the high temperature for about $10 \mathrm{~min}$, and quenched. The glass was cut into bars of similar dimensions $\left(2 \times 1 \times 8 \mathrm{~mm}^{3}\right)$ and polished before further thermal treatment. The crystallisation was carried out in a tube furnace at $750^{\circ} \mathrm{C}$ for 4 (Bi4), 8 (Bi8), 16 (Bi16) and 1200 (Bi1200) min. Low- $T_{\mathrm{c}}$ granular materials were prepared by a surface modification of lead-germanate glasses. The glass was prepared in a conventional way. Milled mixture of powdered $\mathrm{GeO}_{2}$ and $\mathrm{Pb}\left(\mathrm{NO}_{3}\right)_{2}$ after the decomposition at $800^{\circ} \mathrm{C}$ was submitted to a gradual heating from room temperature to $1000^{\circ} \mathrm{C}$. Melted glass was homogenised and then quenched by pouring onto a steel plate. Reduction process was carried out at $673 \mathrm{~K}$ in hydrogen atmosphere. We present result obtained for $\mathrm{Pb}_{0.3} \mathrm{Ge}_{0.7} \mathrm{O}_{1.7}$ samples reduced at $673 \mathrm{~K}$ for $2 \mathrm{~h}(\mathrm{~Pb} 2), 3 \mathrm{~h}(\mathrm{~Pb} 3), 15 \mathrm{~h}$ (Pb15) and $24 \mathrm{~h}(\mathrm{~Pb} 24)$. More structural information of reduced lead-germanate glass has been published elsewhere [8].

The resistivity of low- and high- $T_{\mathrm{c}}$ samples was measured above $4.8 \mathrm{~K}$ and $3 \mathrm{~K}$, respectively.

\section{Results and discussion}

The heat treatment, which was applied to lead-germanate and $(\mathrm{Bi}, \mathrm{Pb})-$ $\mathrm{Sr}-\mathrm{Ca}-\mathrm{Cu}-\mathrm{O}$ glasses, leads to formation of metallic granules distributed in the amorphous matrix. In lead-germanate glasses hydrogen atoms diffusing through the surface part of the glass reduce $\mathrm{Pb}^{2+}$ ions into neutral atoms, which subsequently agglomerate and form metallic granules. In case of $(\mathrm{Bi}, \mathrm{Pb})-\mathrm{Sr}-\mathrm{Ca}-\mathrm{Cu}-\mathrm{O}$ glasses conducting granules formed as a result of high-temperature annealing, which caused the solid state crystallisation. Metallic phases, which form as a result of crystallisation are the oxide superconductors belonging to bismuth family, that is $(\mathrm{Bi}, \mathrm{Pb})_{2} \mathrm{Sr}_{2} \mathrm{CuO}_{x}\left(2201\right.$ with $\left.T_{\mathrm{c}}=10 \mathrm{~K}\right)$, and $(\mathrm{Bi}, \mathrm{Pb})_{2} \mathrm{Sr}_{2} \mathrm{CaCu}_{2} \mathrm{O}_{x}$ $\left(2212, T_{\mathrm{c}}=85 \mathrm{~K}\right)$.

Examples of the microstructure of the studied granular samples are shown in Fig. 1. X-ray diffraction (XRD) analysis showed that the granules seen in the 
AFM images in the low- and high- $T_{\mathrm{c}}$ samples are grains of metallic lead and 2212 crystallites, respectively. The shape of metallic granules is oval while their size depends on the time of heat treatment. Their sizes are of the order of $20-100 \mathrm{~nm}$ and $20-300 \mathrm{~nm}$ in lead-germanate and $(\mathrm{Bi}, \mathrm{Pb})-\mathrm{Sr}-\mathrm{Ca}-\mathrm{Cu}-\mathrm{O}$ glasses, respectively. In all the samples, the heat treatment conditions affect the amount of metallic phases and the granule radius. Generally speaking, the longer annealing or reduction time the larger amount of metallic phases distributed in the form of the larger granules form in the samples.
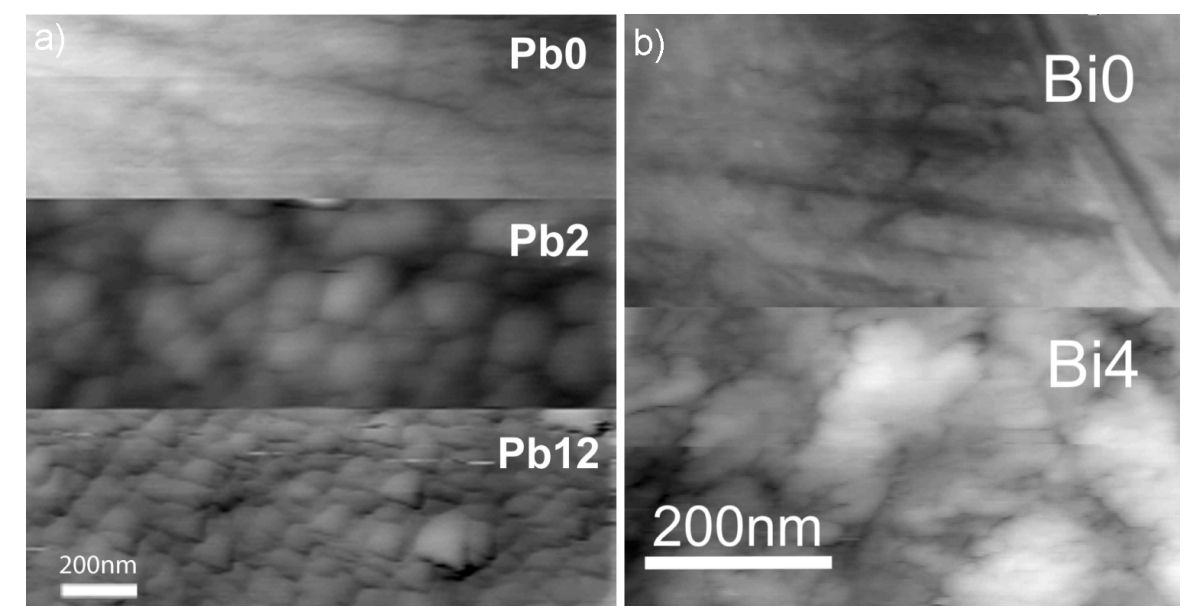

Fig. 1. AFM images of lead-germanate ((a) $\mathrm{Pb} 0-\mathrm{Pb} 15)$ and $(\mathrm{Bi}, \mathrm{Pb})-\mathrm{Sr}-\mathrm{Ca}-\mathrm{Cu}-\mathrm{O}$ ((b) Bi4) modified glasses.

Solid state crystallisation is a process, which proceeds in the whole volume of the material, while the reduction affects mainly the surface layer of the glass. Nevertheless, the modified layer is thick enough that from the point of view of the transport phenomena it may be considered as a 3-dimensional granular system. The exact value of the width of the modified layer is not known, therefore, for these samples, the surface resistivity has been calculated from equation $\rho_{\square}=R l / d$, where $R$ is the resistance of sample, $d$ is the distance between electrodes and $l$ is the length of electrode.

Normal state electrical properties of granular materials are determined by the tunnelling conductivity between the neighbouring grains, which depends on the amount of metallic phase, size of the granules and distance between them. When the conductivity between the grains in the normal state is low, granular material is in the dielectric regime and electrical conductivity occurs through thermally activated tunnelling of electrons between grains [1]. In this case temperature dependence of the resistivity of such materials usually follows the exponential relation. When the conductivity between the metallic grains is larger, the granular material is in the metallic regime. In this case the $\rho(T)$ dependence is weaker than 
exponential for example logarithmic, linear or other [7]. The samples discussed in this work are in the metallic regime. The electrical properties of both groups of materials heat-treated for different periods of time are presented in Figs. 2 and 3 and Table $\mathrm{I}$. Both in the case of crystallised $(\mathrm{Bi}, \mathrm{Pb})-\mathrm{Sr}-\mathrm{Ca}-\mathrm{Cu}-\mathrm{O}$ glasses and reduced lead-germanate glasses the sequence of changes of their electrical properties has several common features. In the early state of growth the materials have large resistivity with a large and negative temperature coefficient of resistivity (e.g. Pb3, Bi4). Further heat treatment causes that a $\rho(T)$ dependence becomes much slower and finally, a change in the slope of $\rho(T)$ and positive temperature coefficients may be observed (e.g. Pb7, Bi1200). It should be also noted that $\rho(T)$ dependence of reduced lead-germanate glasses is close to that in bulk lead (with positive temperature coefficient of resistivity (TCR)), while most $(\mathrm{Bi}, \mathrm{Pb})-$ $\mathrm{Sr}-\mathrm{Ca}-\mathrm{Cu}-\mathrm{O}$ glasses have negative TCR. This difference may be caused by the fact that lead-germanate samples have larger grains than the $(\mathrm{Bi}, \mathrm{Pb})-\mathrm{Sr}-\mathrm{Ca}-\mathrm{Cu}-\mathrm{O}$, therefore they have fewer links between them. Temperature coefficient of resistivity is determined by disorder, quality and the number of the links between grains.

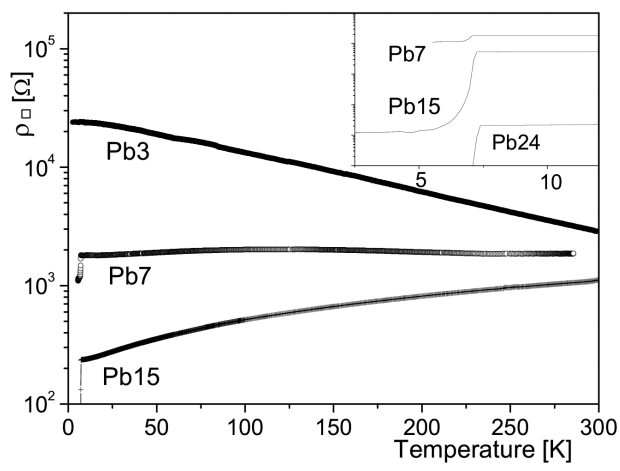

Fig. 2. Temperature dependence of resistivity of lead-germanate glasses reduced in hydrogen. Inset shows the transition into superconducting state.

The superconducting transition in both groups of samples is shown in Figs. 2 and 3. It may be seen that in the high- $T_{\mathrm{c}}$ materials the transition is much wider $(10-20 \mathrm{~K})$ than in the low-ones $(1-2 \mathrm{~K})$. It is consistent with the normal-state electrical conductivity since in the granular materials the width of the superconducting transition is influenced by the same microstructural features than TCR (interfaces between the grains) [9]. Another interesting difference between low- and high- $T_{\mathrm{c}}$ granular metals may be also noted. Non-complete transition into the superconducting state in the low- $T_{\mathrm{c}}$ materials occurs in the sample in which the change from negative to positive TCR is observed, while the high- $T_{\mathrm{c}}$ samples with even quite large negative TCR have complete superconducting transition. Long-range superconducting order in granular superconductors occurs when the Josephson coupling between the grains exceeds the Coulomb charging energy [10]. 


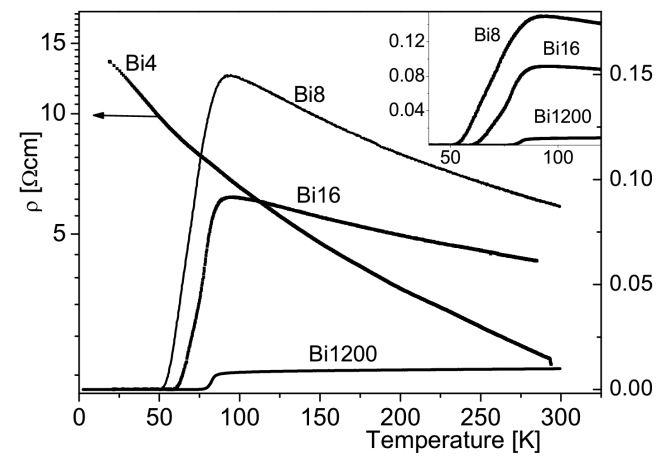

Fig. 3. Temperature dependence of resistivity of $(\mathrm{Bi}, \mathrm{Pb})-\mathrm{Sr}-\mathrm{Ca}-\mathrm{Cu}-\mathrm{O}$ crystallised glasses. Inset shows the transition into superconducting state.

TABLE I

Room temperature resistivity and temperature coefficient of resistivity of granular samples heat-treated in different ways. TCR was estimated as TCR = $\frac{1}{200 \mathrm{~K}} \frac{\rho(300 \mathrm{~K})-\rho(100 \mathrm{~K})}{\rho(100 \mathrm{~K})}$.

\begin{tabular}{c|c|c|c|c|c}
\hline \hline Sample & $\rho_{\square}(300 \mathrm{~K})[\Omega]$ & TCR $\left[10^{-3} / \mathrm{K}\right]$ & Sample & $\rho(300 \mathrm{~K})[\Omega \mathrm{cm}]$ & $\mathrm{TCR}\left[10^{-3} / \mathrm{K}\right]$ \\
\hline $\mathrm{Pb} 3$ & 800 & -3.8 & Bi4 & 2.4 & -3.2 \\
$\mathrm{~Pb} 15$ & 500 & 5 & Bi8 & 0.09 & -2 \\
$\mathrm{~Pb} 24$ & 10 & 8.5 & Bi16 & 0.06 & -1 \\
$\mathrm{~Pb} 48$ & 6 & 9.2 & Bi1200 & 0.01 & 0.8
\end{tabular}

The Josephson coupling energy [11] and the Coulomb charging energy [1] may be estimated from the following relations:

$$
E_{\mathrm{J}}(0)=\frac{\pi}{8} \frac{\hbar}{e^{2}} \frac{\Delta_{\mathrm{s}}(0)}{R_{\mathrm{n}}}, \quad E_{\mathrm{C}}=\frac{e^{2}}{4 \pi \varepsilon \varepsilon_{0}} \frac{s}{d(s+d / 2)},
$$

where $R_{\mathrm{n}}$ is the normal resistance of the junction, $\Delta_{\mathrm{s}}$ is the superconducting energy gap, where $\varepsilon$ is the dielectric constant of the granular composite, $d$ and $s$ are the grain diameter and the junction width, respectively. Lead-germanate samples in comparison with the $(\mathrm{Bi}, \mathrm{Pb})-\mathrm{Sr}-\mathrm{Ca}-\mathrm{Cu}-\mathrm{O}$ samples have larger grain dimensions $(d)$, lower dielectric constant $(\varepsilon)$ and the approximately ten times lower superconducting gap. So that, in order to form a long-range superconducting state lead-germanate granular material has to have lower normal-state resistivity than the granular $(\mathrm{Bi}, \mathrm{Pb})-\mathrm{Sr}-\mathrm{Ca}-\mathrm{Cu}-\mathrm{O}$.

\section{Conclusions}

$(\mathrm{Bi}, \mathrm{Pb})-\mathrm{Sr}-\mathrm{Ca}-\mathrm{Cu}-\mathrm{O}$ materials obtained by solid state crystallisation and lead-germanate glasses reduced in hydrogen may be considered as a $3 \mathrm{D}$ system of grains of a metallic phase embedded in the insulating matrix. They provide 
TABLE II

Summary of the electrical properties of reduced lead-germanate glasses and the $(\mathrm{Bi}, \mathrm{Pb})-\mathrm{Sr}-\mathrm{Ca}-\mathrm{Cu}-\mathrm{O}$ samples subjected to solid-state crystallisation.

\begin{tabular}{l|l|l}
\hline \hline & $\begin{array}{l}\text { Lead-germanate glasses reduced in } \\
\text { hydrogen }\end{array}$ & $\begin{array}{l}\text { (Bi,Pb)-Sr-Ca-Cu-O } \\
\text { crystallised glasses }\end{array}$ \\
\hline Dielectric regime & \multicolumn{1}{|c}{ Hopping conductivity with exponential $\rho(T)$ dependence } \\
\hline Metallic regime & $\begin{array}{l}\text { Negative and positive temperature } \\
\text { coefficient of resistivity }\end{array}$ & $\begin{array}{l}\text { Almost all samples have } \\
\text { negative coefficient of } \\
\text { resistivity }\end{array}$ \\
\hline \multirow{2}{*}{$\begin{array}{l}\text { Superconducting } \\
\text { transition }\end{array}$} & $\begin{array}{l}\text { Samples with positive TCR have a } \\
\text { superconducting transition; }\end{array}$ & $\begin{array}{l}\text { Samples with negative and } \\
\text { positive TCR have a } \\
\text { superconducting transition; }\end{array}$ \\
\cline { 2 - 3 } & $\begin{array}{l}\text { In samples with large resistivity the } \\
\text { transition is not complete; }\end{array}$ & $\begin{array}{l}\text { In all studied samples the } \\
\text { transition is complete; }\end{array}$ \\
\cline { 2 - 3 } & $\Delta T<2 \mathrm{~K}$ & $\Delta T \leq 20 \mathrm{~K}$
\end{tabular}

the opportunity to study the whole variety of electrical properties characteristic of granular and disordered materials.

Summary of the electrical properties of both families of granular materials is collected in Table II. There are shown surprisingly many common features. The differences between low- and high- $T_{\mathrm{c}}$ granular superconductors are caused by either microstructural properties or the value of the superconducting energy gap.

\section{References}

[1] B. Abeles, P. Sheng, M.D. Coutts, Y. Arie, Adv. Phys. 24, 407 (1975).

[2] P. Sheng, B. Abeles, Y. Arie, Phys. Rev. Lett. 31, 44 (1973).

[3] C.J. Adkins, J. Phys. C 1, 1253 (1989).

[4] I.P. Zvyagin, R. Keiper, Phys. Status Solidi B 230, 151 (2002).

[5] A. Gerber, A. Milner, G. Deutscher, M. Karpovsky, A. Gladkikh, Phys. Rev. Lett. 78, 4277 (1997).

[6] T. Chui, G. Deutscher, P. Lindenfeld, W.L. McLean, Phys. Rev. B 23, 6172 (1981).

[7] I.S. Belobrodov, A.V. Lopatin, V.M. Vinokur, K.B. Efetov, Rev. Mod. Phys. 79, 469 (2007).

[8] J. Gackowska, M. Gazda, K. Trzebiatowski, B. Kusz, J. Non-Cryst. Solids 352, 4242 (2006).

[9] P.A. Lee, T.V. Ramakrishnan, Rev. Mod. Phys. 57, 287 (1985).

[10] G. Deutscher, in: Connectivity and Superconductivity in Inhomogeneous Structures, Eds. J. Berger, J. Rubinstein, LNP m62, p. 248, Springer-Verlag, 2000.

[11] B. Abeles, Phys. Rev. B 15, 2828 (1977). 